Galina Petrova (Sankt Petersburg) / Lucinde Braun (Regensburg)

\title{
Berlioz und Russland - neue Ansätze, neue Quellen ${ }^{1}$
}

Das Thema „Berlioz und Russland“ ist in der Musikwissenschaft verschiedentlich dargestellt worden. Nimmt man neuere Einzeluntersuchungen zur Hand, so fällt jedoch auf, dass die vor allem auf Berlioz' eigener Schilderung beruhende Faktenlage ${ }^{2}$ kaum erweitert wird. Außerdem werden bestimmte Elemente eines bis ins 19. Jahrhundert zurückreichenden Diskurses weitergeschrieben, ohne dass dieser Umstand reflektiert würde. ${ }^{3}$ Ziel unseres Aufsatzes ist es, an zwei Beispielen - der Widmungsgeschichte der Symphonie fantastique und den persönlichen Netzwerken, die Berlioz mit Russland verbanden - aufzuzeigen, wie wenig erschlossen zahlreiche Teilaspekte der Thematik noch immer sind. ${ }^{4}$

\section{Die Widmung der "Symphonie fantastique“}

Eine besonders eklatante Geschichtsverfälschung, die der sowjetischen Musikwissenschaft anzulasten ist, betrifft das Verhältnis des französischen Komponisten zur russischen Zarendynastie. Hector Berlioz hat seine 1830 entstandene und uraufgeführte Épisode de la vie d'un artiste (Symphonie fantastique) dem russischen Zaren Nikolaj I. gewidmet. Aus ideologischen Gründen hat die sowjetische Musikwissenschaft keinen Wert darauf gelegt, diesen Umstand besonders hervorzukehren: Er blieb in Russland auf Dauer vergessen. In Anna Chochlovkinas Berlioz-Biographie, über Jahrzehnte hinweg dem wichtigsten Referenzwerk für russischsprachige Forscher, fehlt so jeglicher Hinweis auf die Widmung der Symphonie

1 Die von Galina Petrova durchgeführte Untersuchung wurde von der Russischen Stiftung für Geisteswissenschaften (RGNF) im Rahmen des Forschungsprojekts „Russisch-französische Musikkontakte: Hector Berlioz in Petersburg" unter der Projektnummer 14-04-00138a gefördert. Im Zuge der Übersetzung ins Deutsche durch Lucinde Braun ist es zu einer starken inhaltlichen Erweiterung und Neuausrichtung der Studie gekommen, so dass der Text unter zwei Autorennamen erscheint.

2 Vgl. das Kapitel „To Russia“ in: David Cairns, Hector Berlioz. Servitude and Greatness 1832-1869, Berkeley 1999, S. 366-390.

3 Vgl. L.G. Dan'ko, Konstanty večnosti (k 200-letiju G. Berlioza), in: Russko-francuzskie muzykal'nye svja$z i$, hrsg. von Valerij Smirnov, Sankt Petersburg 2003, S. 19-29; Linda Edmondson, „Berlioz und Cultural Politics in Mid-Nineteenth-Century Russia“, in: The musical Voyager: Berlioz in Europe, hrsg. von David Charlton und Katharine Ellis, Frankfurt a. M. u.a. 2007, S. 95-113, Elena Dolenko, „Hector Berlioz as Reflected in the Russian Press of his Time“, in: ebd., S. 114-123.

4 Der Impuls, Quellenforschungen zum russischen Musikleben des 19. Jahrhunderts in die Überlegungen einzubeziehen, geht vom Russischen Institut für Geschichte der Künste (Rossijskij institut istorii iskusstv, Sankt Petersburg) aus, an dem seit den 1990er Jahren eine Aufarbeitung der interkulturellen Petersburger Musikgeschichte betrieben wird. Zu Berlioz sind in diesem Zusammenhang folgende Beiträge entstanden: Galina Petrova, „Posvjaščenie ,Fantastičeskoj simfonii` Gektora Berlioza Nikolaju I. Uspech ili neuspech?", in: Muzyka v kul'turnom prostranstve Evropy - Rossii. Sobytija. Ličnost. Istorija, hrsg. von Natalija Ogarkova, Sankt Petersburg 2014, S. 104-118; „Zabytoe pis'mo: G. Berlioz - A.F. L’vovu (k istorii pervogo vizita Gektora Berlioza v Rossiju)“, in: Starinnaja muzyka, 2014, Nr. 4, S. 24-26; „Neizvestnoe pis'mo Berlioza“, in: Starinnaja muzyka, 2015, Nr. 3, S. 25-27. 
fantastique an den Zaren. ${ }^{5}$ Auch die in der Sowjetunion erschienenen Partiturausgaben des Werks schwiegen sich darüber aus. ${ }^{6}$

In der sowjetischen Berlioz-Forschung der 1920-30er Jahre war die Frage nach dem politischen Standpunkt des Franzosen zu einer Grundsatzfrage geworden, die sich nicht bloß als Angelegenheit privater Vorlieben ansehen ließ. Die Beurteilung von Berlioz' Schaffen wurde entscheidend für seine Akzeptanz im musikalischen Kanon der neuen Gesellschaft. In ihrer Untersuchung zur Mythologisierung der musikalischen Klassik in der Sowjetunion gibt Marina Raku die wichtigsten Positionen der in den 1920-30er Jahren geführten Debatte um einen ideologisch korrekten Umgang mit der Epoche der Romantik wieder, die prinzipiell als eine Phase des Niedergangs und der „Flucht vor der Wirklichkeit“ eingestuft wurde. ${ }^{7}$ Der Musikkritiker Ivan Sollertinskij versuchte 1932, Berlioz' Schaffen für den sowjetischen Musikbetrieb zu legitimieren, indem er auf Berührungspunkte mit der Musik der französischen Revolution sowie auf die Fortschreibung des ,revolutionären Erbes Beethovens hinwies. ${ }^{8}$ Sein kluger, analytisch differenzierter Essay endet mit dem programmatischen Satz:

„Sein Platz, der Platz eines genialen Neuerers und wahren Revolutionärs in der Musik, ist in den vordersten Reihen jenes musikalischen Erbes, das als unverzichtbarer Bestandteil in die sowjetische Musikkultur eingeht. Denn Berlioz hat dem sowjetischen Hörer etwas zu sagen und dem sowjetischen Komponisten etwas beizubringen."

Von Vertretern der Kulturbürokratie konnte ein solcher Rekurs auf gängige ideologische Floskeln jedoch mit wenigen Worten hinweggewischt werden und als das enttarnt werden, was er letztlich darstellte: den Versuch der Rettung eines geschätzten, aber nicht parteikonformen Künstlers. So hieß es im offiziellen Vorwort zu Sollertinskijs Essayband:

„Sollertinskij überschätzt zweifellos die revolutionäre Bedeutung von Berlioz' Schaffen in der ersten Hälfte seines Lebens (bis Mitte der 40er Jahre). Das vermeintlich Revolutionäre an Berlioz reichte, wie generell bei den Romantikern, schon in dieser Periode nicht weiter als bis zu einem aufgesetzten Frondeurtum und dem äußerlichen Protest eines individualistischen Intelligenzlers, der sich gegen den Alltag der bürgerlichen Seinsweise auflehnte. "10

Die Brisanz solcher Auseinandersetzungen macht es verständlich, dass man an so heikle Fragen wie die Widmung der Symphonie fantastique lieber nicht rührte. ${ }^{11}$

5 Anna Chochlovkina, Berlioz, Moskau 1960.

6 Vgl. Gektor Berlioz, Fantastičeskaja simfonija (Ėpizod iz žizni artista). Partitura, Vorwort von K. Sakva, Moskau 1959.

7 Vgl. Marina Raku, Muzykal’naja klassika v mifotvorčestve sovetskoj epochi, Moskau 2014, S. 101-117. Das Zitat auf S. 104 stammt aus E. Braudo, Vseobščaja istorija muzyki, Bd. 2, Moskau 1925, S. 168.

8 Vgl. Iwan Sollertinski, „Hector Berlioz“, in: ders., Von Mozart bis Schostakowitsch. Essays, Kritiken, Aufzeichnungen, hrsg. von Michail Druskin, Leipzig 1979, S. 68-77.

9 Ebd., S. 113.

10 „Соллертинский несомненно переоценивает революционное значение творчества Берлиоза в первую половину его жизни (до середины 40-х годов). Мнимая революционность Берлиоза, как и всех вообще романтиков, уже в этот период не шла дальше показного фрондерства и внешнего протеста интеллигента-индивидуалиста, отщепенца против обыденного буржуазного существования.“ Einführung zu: Ivan Sollertinskij, „Gektor Berlioz“, in: ders., Problemy muzykoznanija, Moskau 1932, S. 2, zitiert nach: Raku, S. 105.

11 Man konnte Hinweise darauf allerdings in Quellenpublikationen finden, z. B. im Nachdruck von Odoevskijs Rezension des ersten Petersburger Konzerts von Berlioz, in der das Programm des zweiten Konzerts angekündigt wurde: „In ihm wird unter anderem [...] die dem Herrscher-Imperator 
Grundsätzlich ist zu bemerken, dass das Faktum der Dedikation an Zar Nikolaj I. für die Konstruktion einer kongruenten Berlioz-Biographie keineswegs unentbehrlich erscheint - ganz im Gegenteil. Der Komponist selbst begleitete die Zueignung der Ouvertüre Roi Lear an Armand Bertin mit einem Kommentar, der vor allem den Wert des Kunstwerks und die freundschaftliche Verbundenheit zu dem Dedizienten hervorhob: „La dédicace d'un morceau de musique est un hommage banal qui n'a de prix que par le mérite de l'ouvrage, mais j'espère que vous accepterez celle-ci comme l'expression de la reconnaissante amitié que je vous ai vouée depuis longtemps." 12

Ganz explizit wies Berlioz den Gedanken einer Widmung an einflussreiche Herrscherpersönlichkeiten seiner Zeit im Dezember 1847 gegenüber Franz Liszts Sekretär Gaetano Belloni zurück:

„Pour revenir aux dédicaces, dites à Liszt que je regrette de n'avoir pas pu adresser galamment Roméo à la personne qu'il voulait m'indiquer, et que pour Faust, quand on le publiera, j'ai en vue un prince de l'art que je préfere de beaucoup à tous les princes de terre, même au prince héréditaire de Weimar qui est fort aimable et dont j'ai fait la connaissance à Paris, il y a deux ans: c'est à Liszt que je comptais dédier cette partition, et pour tous les cadeaux princiers imaginables, je ne renoncerais à me donner ce plaisir."13

In Anbetracht solcher Äußerungen erscheint die Tatsache, dass die Symphonie fantastique, dieses Manifest einer neuen, romantischen Programmmusik, ausgerechnet Zar Nikolaj I. gewidmet wurde, als geradezu kurios. Denn das Werk wurde nicht etwa einem der großen Künstler der Zeit zugeeignet, sondern dem sprichwörtlich größten „Beamten ' unter den regierenden Herrschern. Rezeptionsgeschichtlich überrascht es daher nicht, dass auch nichtsowjetische ältere Editionen diesen Umstand wenig hervorheben. Im Gegensatz zu den von uns überprüften Partiturdrucken der Verlage Brandus (Paris) und Breitkopf \& Härtel (Leipzig), die stets die Widmungszeile enthalten, ${ }^{14}$ verzichteten schon die Herausgeber der Liszt'schen Klavierfassung auf den Widmungstext - auf dem Titelblatt stechen so vornehmlich die zwei Künstlernamen Berlioz und Liszt ins Auge. ${ }^{15}$ Ebenso wenig streicht die für ein breites Publikum gedachte Taschenpartitur-Ausgabe des Verlags Ernst Eulenburg die Tatsache eigens heraus. ${ }^{16}$

Es ist kein Geheimnis, dass Berlioz' Verhalten zu den Mächtigen seiner Zeit von Ambivalenz geprägt war. In den Jahren zwischen 1840 und 1847 hatte der Komponist mit „fürstlichen Geschenken“ einige Erfahrungen gesammelt. Besonders gut erforscht ist die Widmung des Traité de l'instrumentation an den preußischen König Friedrich Wilhelm IV.

gewidmete Symphonie fantastique aufgeführt werden.“ („В нем исполнены будут между прочим [...] Фантастическая симфония, посвященная государю императору.“) Vladimir F. Odoevskij, Muzykal'no-literaturnoe nasledie, Moskau 1956, S. 225.

12 Brief an Armand Bertin, 12. Februar 1840, in: Hector Berlioz, Correspondance générale, hrsg. von Pierre Citron, Bd. 2: 1832-1842, Paris 1975, S. 629 [im Folgenden: CG 2].

13 Brief an Gaetano Belloni, London, 19.12.1847, Correspondance générale, hrsg. von Pierre Citron, Bd. 3: 1842-1850, Paris 1978, S. 490 [im Folgenden: CG 3].

14 Vgl. den Wortlaut der Widmung in: Hector Berlioz, New Edition of the Complete Works, Kassel u.a. 1972, Bd. 16, S. XXX [im Folgenden: NBE 16].

15 Vgl. Hector Berlioz, Episode de la Vie d'un Artiste. Grande Symphonie fantastique. Partition de piano. Seconde édition revue et corrigée par Fr. Liszt, Leipzig: F.E.C. Leuckart, Plattennr. F.E.C.L.2893.

16 Vgl. die Edition in der Reihe Eulenburg's kleine Orchester-Partitur-Ausgabe, Leipzig: Ernst Eulenburg [1900], Plattennr. E.3955 D. Die Ausgabe verzeichnet die Widmung zwar auf der Werkübersicht, nicht jedoch auf dem Titelblatt der Partitur. Auch das Vorwort von Arthur Smolian erwähnt den Umstand nicht. 
Alle einzelnen Schritte dieses Vorgangs lassen sich in der Korrespondenz des Komponisten dokumentieren: die Vermittlung einer Audienz durch Alexander von Humboldt, den Berlioz 1842 in Paris kennengelernt hatte; ${ }^{17}$ der Besuch am preußischen Hof nach der Ankunft in Berlin, bei dem Berlioz die Erlaubnis erhielt, dem König den Traité zuzueignen; ${ }^{18}$ die Übersendung von drei Druckexemplaren im Dezember 1843 nach Berlin, ${ }^{19}$ von denen eines durch Alexander von Humboldt dem König überreicht wurde. ${ }^{20}$ Friedrich Wilhelm IV., ein glühender Musikliebhaber und Verehrer Berlioz', schrieb dem Komponisten schließlich am 23. März 1844 ein eigenhändiges Dankschreiben, das sich ebenfalls erhalten hat. ${ }^{21}$

Im Falle der Symphonie fantastique liegen vergleichbare Informationen nicht vor. Obwohl in der westlichen Berlioz-Literatur die Tatsache der Widmung an Nikolaj I. allgemein bekannt ist, wird der Sachverhalt in der neuen kritischen Ausgabe der Symphonie fantastique lediglich in einem knappen Absatz unter der Überschrift "Titel und Widmung“ abgehandelt. ${ }^{22}$ Auch in David Cairns' Monographie fällt der Blick nur kurz auf die Widmung der Symphonie fantastique an den russischen Zaren. ${ }^{23}$ Linda Edmondson wiederum legt den Schwerpunkt ihres Beitrags „Berlioz und Cultural Politics in Mid-Nineteenth-Century Russia" auf die kulturpolitische Situation unter Zar Nikolaj I., die sie mit einer Fülle allgemeinhistorischer Details vor allem wohl im Blick auf einen westlichen Leserkreis umreißt. Im Kontext dieser Überlegungen weist Edmondson lediglich darauf hin, dass „Berlioz had paved the way to Russia by dedicating the Symphonie fantastique, when it was finally published in 1845 , to Nicholas I“. 24

Auf welche Weise jedoch und aus welchen Gründen Berlioz beschloss, seine Symphonie ausgerecht Nikolaj I. zuzueignen, dazu fehlt es an genaueren Überlegungen. Als einzige Erklärung findet man in der kritischen Ausgabe der Symphonie fantastique einen Verweis auf den mutmaßlichen ersten Kontakt des Komponisten zum russischen Zaren, der Berlioz 1843 den Auftrag erteilt haben soll, eine Bearbeitung russischer Kirchenchoräle anzufertigen. ${ }^{25}$ Dieser aus einer Zeitschriftennotiz bekannte Aspekt ist bislang nicht weiter verfolgt worden. Als einzige Anspielung auf das Ereignis wird Berlioz' Brief an seine Schwester Nancy vom 6./7. September 1843 zitiert: „Si l'Empereur de Russie me veut je me vends à lui; il faut que je prenne des informations..." 26

Versuchen wir, die Geschichte von Drucklegung und Widmung der Symphonie fantastique nochmals genauer aufzurollen. Berlioz' Arbeit an der Drucklegung der Partiturausgabe

17 Vgl. den Brief an den Vater, 14.3.1843, CG 3, S. 79f.: „Ce voyage sera très important, j’ai à y voir le Roi de Prusse pour lui offrir la dédicace de mon traité d'instrumentation. M. de Humboldt sera mon introducteur."

18 Vgl. den Brief an den Vater, 4./5.6.1843, CG 3, S. 98, in dem über den ehrenhaften Empfang durch den König und Alexander von Humboldt berichtet wird.

19 Vgl. den Brief an Giacomo Meyerbeer, 23.12.1843, CG 3, S. 146.

20 Vgl. den Brief an die Schwester, 5.1.1844, CG 3, S. 156: „Je viens d'envoyer au Roi de Prusse mon traité d'Instrumentation; voyons s'il (le Roi) se mettra en frais de Diamants. C'est Meyerbeer qui l'a emporté (le traité) et M. A. de Humboldt le présentera."

21 Vgl. CG 8, S. 236. Vgl. auch die Zusammenfassung der Widmungsgeschichte in: Hector Berlioz, Grand traité d'instrumentation et d'orchestration modernes, hrsg. von Peter Bloom, Kassel u. a. 2003 (NBE 24), S. XXXII.

22 Vgl. NBE 16, S. XXX.

23 Vgl. Cairns, Servitude and Greatness, S. 366.

24 Edmondson, S. 102. Zur russischen Berlioz-Rezeption zwischen 1833 und 1869 siehe auch Dolenko.

25 NBE 16, S. XXX.

26 CG 3, S. 112. 
begann 1844. Bereits am 26. Juli dieses Jahres erwähnt der Komponist, dass der Stich abgeschlossen sei: „La Symphonie Fantastique est gravée et paraîtrait dans un mois si j'avais le temps de corriger les épreuves." 27

An dieser Stelle kam es jedoch zu einer längeren Unterbrechung, denn die Partitur sollte erst 1845 im Verlag Schlesinger erscheinen. Die Gründe für diesen Stillstand hat man zunächst in der Krise zu suchen, die der Komponist im Sommer 1844 durchlebte. Erst Mitte Oktober 1844 kehrte er nach längerem Aufenthalt in Nizza nach Paris zurück. ${ }^{28}$ Berlioz war nun wieder bereit, sich auf seine professionellen Tätigkeiten einzulassen und stürzte sich in eine Vielzahl von Projekten. ${ }^{29}$ Neben kompositorischen Vorhaben und der Organisation der Konzertserie im Cirque Olympique stand nun auch irgendwann die Korrektur der Druckfahnen an.

Mit der exakten Chronologie der Drucklegung der Erstausgabe hat man sich bislang kaum beschäftigt. Zu den Quellen zählt vor allem ein in der Berlioz-Philologie seit langem bekannter Vorabdruck („advance edition“, $\mathrm{P}_{1}$ ) mit handschriftlichen Korrekturen des Autors. Er ist in unserem Zusammenhang insofern von besonderem Interesse, als auf dem Titelblatt noch keine Widmung figuriert. ${ }^{30}$ Erst der definitive Druck $\left(\mathrm{P}_{2}\right)$ enthält neben einigen kleineren Korrekturen im Notentext auch im Titel die Formulierung der Zueignung:

„Episode / de la vie d’un Artiste / Symphonie / Fantastique en cinq parties/ Dédiée à Sa Majesté Nicolas I/ Empereur de toutes les Russies / Par / Hector Berlioz / Op. 14 / Paris / Maurice Schlesinger."31

Im Werkverzeichnis wird die „,advance edition“ annäherungsweise auf Ende 1844 datiert. ${ }^{32}$ Nicholas Temperley äußert sich im kritischen Bericht zur Symphonie fantastique vorsichtiger. Er nennt als Datum den Zeitraum „late 1844 or early $1845^{\prime 33}$. Seine Formulierung in der Einleitung weist darauf hin, dass es sich um reine Vermutung handelt. ${ }^{34}$ Nicht berücksichtigt wurde offenbar eine wichtige Datierungshilfe, nämlich die Chronologie der Schlesinger'schen Plattennummern. Wesentlich früher als die Partitur waren demnach die Druckplatten zu den Orchesterstimmen entstanden. ${ }^{35}$ Deren Plattennummer M.S. 4052 gehört in das Jahr 1844, in dem die Platten M.S. 4018-4105 hergestellt wurden. Geht man von einer annähernd gleichmäßigen Verteilung der Nummern auf die Monate des Jahres aus, so erhält man für die Nummer 4052 einen Termin im Juli. Berlioz' Bemerkung vom 26. Juli 1844, die Symphonie sei gestochen und könne in einem Monat erscheinen, dürfte sich also auf die Orchesterstimmen beziehen. Die Plattennummer M.S. 4208, die sowohl für den Vorabdruck $\left(\mathrm{P}_{1}\right)$ als auch für den definitiven, mit leichten Korrekturen versehenen Erstdruck $\left(\mathrm{P}_{2}\right)$ der Symphonie fantastique Verwendung fand, fällt dagegen erst in das Jahr 1845, welches die Plattennummern M.S. 4140-4309 umfasst. Nimmt man abermals eine regelmäßige Verlagsproduktion an, so wären im Schnitt monatlich 14 Drucke entstanden.

27 Brief an Robert Griepenkerl, Paris, 26.7.1844, CG 3, S. 193.

28 Vgl. den Brief an Buy-Fournier, ca. 15.-18.10.1844, CG 3, S. 201.

29 Vgl. den Brief an Nanci Pal, 5.11.1844, CG 3, S. $203 \mathrm{f}$.

30 Vgl. Cecil Hopkinson, A Bibliography of the Musical and Literary Works of Hector Berlioz 1803-1860, Second edition, Turnbridge Wells 1980, Abb. IIIa.

31 Ebd., Abb. IIIb.

32 Vgl. Dallas Kern Holoman, Catalogue of the works of Hector Berlioz, Kassel u.a. 1987, S. 90.

33 NBE 16, S. 172.

34 Siehe den Kommentar ebd., S. XIII: „The dating of the advance issue is uncertain [...].“

35 Vgl. Dictionnaire des éditeurs de musique française, Bd. 2, hrsg. von Anik Devriès und François Lesure, Genf 1988, S. 390. Im Werkverzeichnis werden die Orchesterstimmen dagegen auf 1845 datiert, vgl. Holoman, S. 91. 
Bei dieser rein rechnerischen Verteilung müssten die Platten für die Partiturausgabe der Symphonie fantastique ungefähr im Mai 1845 gestochen worden sein.

Wichtig für die zeitliche Einordnung der Dedikation ist der Umstand, dass der MaiTermin, an dem die Stichvorlage erstellt wurde, bereits in unmittelbarer Nähe zu den ersten Annoncen des Verlagshauses Schlesinger vom 4. und 18. Mai 1845 steht, in denen das neue Werk angekündigt wird. ${ }^{36}$ Da hier noch keine Preise genannt werden, dürften sie sich auf $\mathrm{P}_{1}$ beziehen. Erst am 22. Juni 1845 erschien eine Anzeige, ${ }^{37}$ die als Preise 40 fr. für die Partitur und $40 \mathrm{fr}$. für die Stimmen anführt wie auf dem Titelblatt von $\mathrm{P}_{2}$. Zu diesem Zeitpunkt dürfte also der definitive Druck vorgelegen haben, der auch die Widmung enthält.

Die Entscheidung, die Dedikation an Zar Nikolaj auf das Titelblatt der bereits gravierten Partitur zu setzen, lässt sich damit auf eine relativ kurze Phase einengen - den Zeitabschnitt zwischen Anfang Mai (Herstellung von $\mathrm{P}_{1}$, noch ohne Widmungszeile) und Mitte Juni 1845 (Annonce von $\mathrm{P}_{2}$, mit Widmungszeile). Unmittelbar zuvor hatte der französische Komponist ein auffallend starkes Engagement für die Sache der russischen Musik an den Tag gelegt. Berlioz hatte am 16. März und 6. April Werke des gerade in Paris weilenden Komponisten Michail Glinka in die Programme seiner Konzerte im Cirque Olympique aufgenommen. In einem Feuilleton im Journal des Débats am 16. April äußerte er sodann seine Bewunderung für die Kunst des russischen Kollegen, nachdem er Glinka um Informationen zu seiner Biographie, seinem Euvre und der russischen Musik allgemein gebeten hatte. ${ }^{38}$

In seinen Briefen und Memoiren hat Glinka Hinweise darauf gegeben, dass das Interesse, das Berlioz ihm entgegenbrachte, mit den Plänen des Franzosen zu einer großen Russland-Reise koinzidierte. Berlioz wiederum führt Glinka und Leopold von Meyer - dessen Marche marocaine er ebenfalls in seiner Konzertserie vorgestellt hatte - als Personen an, die ihn ermutigt hatten, dieses Projekt zu realisieren. ${ }^{39}$ Man kann nur vermuten, dass in diesem Kreis von Musikern die Idee geboren wurde, die gerade zum Druck vorbereitete Symphonie fantastique als Mittel zu verwenden, um die Aufmerksamkeit des Zaren auf sich zu lenken und in Kontakt zur Bürokratie des Zarenhofs zu treten. Üblich war bei solchen Prozeduren eine offiziell erteilte Erlaubnis, den Namen des Zaren auf das Titelblatt zu setzen. Eingereicht werden musste dazu ein Vorabdruck, der der Zensur zur Begutachtung vorgelegt wurde. Das Warten auf einen positiven Bescheid dürfte dazu geführt haben, dass der schon im Mai annoncierte Partiturdruck erst Ende Juni mit dem Widmungstext auf dem Titelblatt erscheinen konnte. Mit wessen Hilfe Berlioz dies bewerkstelligt hat, wissen wir bislang allerdings nicht.

Stärker konturieren lässt sich dagegen die erste Russlandreise des Komponisten, die offenbar strategisch durch die Widmung an den Zaren befördert werden sollte. Cairns hat in seiner Berlioz-Monographie die Vermutung ausgesprochen, der Komponist habe seine 1847 durchgeführte Russlandtournee im Herbst 1845 zu planen begonnen. Er stützt sich dabei auf eine von Berlioz an die Bibliothek des Pariser Konservatoriums gerichtete schriftliche Bitte um Beurlaubung zwecks einer Reise nach Österreich und Russland. ${ }^{40}$ Studiert man Berlioz Korrespondenz, so lässt sich leicht nachweisen, dass der Gedanke wesentlich früher aufscheint. Bereits am 17. Mai 1845 antwortete Berlioz Franz Liszt auf dessen Anfrage nach einer Aufführung seines Requiems in Bonn ausweichend, denn er suche nach Mitteln für

36 Vgl. Revue et gazette musicale, 4.5.1845, Nr. 18, S. 144; La France musicale, 18.5.1845, Nr. 20, S. 160.

37 Vgl. Revue et gazette musicale, 22.6.1845, Nr. 25, S. 208.

38 Vgl. den Brief an Michail Glinka, Paris, 25.3.1845, CG 3, S. 237.

39 Vgl. den Brief an Aleksej L'vov, Paris, 1.8.1845, CG 3, S. 270.

40 Vgl. Cairns, Berlioz. Servitude and Greatness, S. 366. 
eine Russlandreise im kommenden Winter. ${ }^{41}$ Dieser Brief fällt in die beschriebene Schlüsselzeit im Mai 1845, als die Partitur der Symphonie fantastique bereits gestochen war, das Titelblatt mit der Widmung jedoch noch nicht erscheinen konnte. Dass es aber auch zu diesem Termin einen längeren Vorlauf gab, belegen zwei weitere Quellen. Félix Marmion, der Onkel des Komponisten, berichtete seiner Nichte Nancy Pal am 25. April von den Fragen, die ihren Bruder gerade beschäftigten:

„Informé que la curiosité est puissamment excitée sur son compte en Russie, il est assez tenté d'en essayer. Mais il y a de grandes difficultés à cause de l'énorme distance qu'il faut parcourir par terre, avec tout son attirail de musique; attendu que la saison des concerts étant exclusivement dans le carême, il faudrait partir l'hiver. La navigation n'ayant pas lieu à cause des glaces, il faut renoncer aux bateaux à vapeur et faire cet énorme trajet en voiture ou en traîneau. " 42

Der Brief liefert einen klaren Anhaltspunkt dafür, dass Berlioz über ein starkes, von Russland ausgehendes Interesse an seiner Person informiert war und bereits Erkundigungen zum günstigsten Zeitpunkt von Konzerten und dem beschwerlichen Reiseweg eingezogen hatte. Lange bekannt, aber im Rahmen unserer Fragestellung nicht beachtet ist zudem ein Brief, den Michail Glinka am 27. Februar 1845 aus Paris an seinen Schwager Victor Fleury nach Russland schickte. Er berichtet darin zum ersten Mal davon, dass seine Werke in der von Berlioz organisierten Konzertreihe aufgeführt werden sollten, und fügt die vertrauliche Bemerkung hinzu: „A vous, je vous dirai pourtant que m-r Berlioz a été d'abord très froid à mon égard, et qu'il ne s'est empressé à me rendre ce service que parce qu'il a en ce moment des projets sur la Russie. “ ${ }^{3}$ Demnach trug sich Berlioz schon im Februar mit dieser Idee, die - wie wir noch sehen werden - noch um einiges früher in sein Gesichtsfeld gelangt war.

Das folgende Dokument, das die Überlegungen über eine Konzertreise nach Sankt Petersburg bestätigt, ist Berlioz' Brief an Aleksej L'vov vom 1. August 1845. Hier ist nun schon ganz konkret von „des concerts en grand à Pétersbourg pendant les mois de novembre et de décembre“ 44 die Rede. Und auch als der Komponist während seiner Konzertreise nach Bonn eine Einladung erhielt, nach Wien zu kommen, teilte er seiner Schwester mit: „Les Viennois qui étaient là m'ont tant fêté et engagé à venir chez eux que je m’y suis décidé et que je me rendrai à Vienne avant d'aller en Russie quand j'aurai terminé ce que j’entreprends ici.“45 Dieser Brief vom 26. August 1845 liefert das letzte eigene Zeugnis des Komponisten für den Russlandplan der Saison 1845/46. Aufgegeben wurde das Projekt, weil die HerbstReise nach Österreich sich immer mehr ausdehnte und weitere Konzerte in Ungarn, Böhmen und Deutschland zustande kamen, so dass Berlioz letztlich erst Anfang Mai 1846 in seine Heimatstadt Paris zurückkehrte.

Die Durchsicht der russischen Presse macht deutlich, dass man im Zarenreich von Berlioz' ursprünglichem Vorhaben informiert war. Einen direkten Hinweis findet man in der Publikation der Reiseaufzeichnungen von Viktor Kažinskij, der den Fürsten Aleksej L'vov als Sekretär nach Deutschland begleitet hatte. Der 1845 in der Zeitschrift Biblioteka dlja čtenija erschienene Bericht ist mit verschiedenartigen Kommentaren durchsetzt. So wird

41 Vgl. den Brief an Franz Liszt, Paris, 17.5.1845, CG 3, S. 246.

42 Félix Marmion an Nancy Pal, 25.4.1845, <http://www.hberlioz.com/famille/bnffamille.htm\#27438>, 24.4.2016.

43 Brief an Victor Fleury, Paris 15. / 27.2.1845, in: Michail I. Glinka, Literaturnye proizvedenija i perepiska, Bd. 2a, Moskau 1975, S. 194.

44 CG 3, S. 271.

45 Brief an Nanci Pal, Frankfurt, 26.8.1845, CG 3, S. 277. 
Kažinskijs Darstellung der italienischen Opernorchester in Deutschland durch die plötzliche Bemerkung unterbrochen: „Übrigens! Berlioz macht sich gerade aus Paris auf den Weg nach Wien, und von dort wird er im Januar oder Februar nach Petersburg kommen. Was für ein Dirigent! “46 Diese vermutlich auf Kažinskij oder seinen Brotgeber Lvov zurückgehende Information leitet einen emotionalen Ausruf mit einem direkten Apell an den französischen Musiker ein:

„Oh, würde er doch bei uns bleiben und zur Vervollkommnung der italienischen Oper, die der Vollkommenheit so nahe ist, den Marschallstab des Orchesters in seine Hände nehmen! Bleiben Sie bei uns, monsieur Hector. Sie werden keinen Schaden haben: eine Fuhre Bouquets für Sie nach dem ersten Erklingen der Ouvertüre zu Don Juan. Wo gibt man Ihnen so viel?“47

Die hochfliegenden und vermutlich wenig begründeten Pläne, den Kapellmeisterposten an der Kaiserlichen italienischen Oper zu übernehmen, weisen stark auf L'vov hin, der Berlioz auch später noch als Kandidaten für eine Umgestaltung der russischen Musiklandschaft im Blick haben sollte. Dass Berlioz zumindest als Dirigent nach Russland kommen könne, hoffte noch im Januar 1846 die Zeitschrift Repertuar i panteon. Im Zusammenhang mit einer Biographie des Komponisten konnte man hier lesen: „Gegenwärtig reist Berlioz durch Deutschland; er war in Wien und Prag und schaut vielleicht auch bei uns in Petersburg vorbei. “ 48

Der Komponist selbst muss allerdings zum Schluss gekommen sein, dass er die Fortsetzung seiner Tournee nach Russland im anbrechenden Frühjahr 1846 nicht mehr würde durchführen können. Der nächste bekannte Schritt in der Widmungsgeschichte der Symphonie fantastique hat als Kulisse so die Stadt Prag. In seinem hier am 16. April 1846 abgefassten Brief an Joseph d'Ortigue erwähnt Berlioz im Postskriptum, dass er ein Geschenk von Nikolaj I. erhalten habe: „L'empereur de Russie et le Prince d'Hechingen viennent de m'envoyer chacun un fort beau présent, (bague de Diamants et Tabatière).“49

Im Rahmen unserer Recherchen im Russischen historischen Staatsarchiv (Rossijskij gosudarstvennyj istoričeskij archiv, im Folgenden: RGIA) sind wir im Fond des Hofministeriums auf Quellen gestoßen, die die Chronologie der Widmung an diesem Punkt ein wenig genauer erhellen. Die Akte „Über die dem Kaiserlichen Herrscher vom Komponisten Berlioz überreichte Symphonie und das ihm gewährte Geschenk "50 enthält die Korrespondenz, die der Kaiserliche Hofminister, Graf Vladimir Fedorovič Adlerberg, mit dem Direktor der Kaiserlichen Theater, Aleksandr Michajlovič Gedeonov, bezüglich der Symphonie fantastique „des Komponisten Berlioz“ führte. Aus dem ersten Schreiben, das Gedeonov am 28. Februar /

46 „Кстати! Берлиоз отправляется из Парижа в Вену, а оттуда, в январе или феврале приедет в Петербург. Вот дирижер!“ „Notatki, e.t.c. (Dnevnikovye zapiski muzykal’nogo putešestvija po Germanii, soveršennogo v 1844 Viktorom Kažinskim)“, in: Biblioteka dlja čtenija 1845, Bd. 73, Abt. V, S. 18.

47 „О, если бы он остался у нас, и, для совершенства итальянской оперы, которая так близка к совершенству, принял бы в свои руки фельдмаршальский жезл оркестра! Останьтесь у нас, monsieur Hector. Не будете в убытке: воз букетов вам, после первого разыгрывания увертюры Дон-Жуана. Где вам дадут столько?“ Еbd., S. 18f.

48 „В настоящее время Берлиоз путешествует по Германии, был в Вене и в Праге, и, может быть, заглянет и к нам в Петербург.“ Repertuar i panteon, 13 (1846), 1. Buch, S. 235.

49 CG 3, S. 337.

50 „О поднесенной Государю Императору композитором Берлио симфонии и пожалованном ему подарке“, RGIA, fond 472, opis' 17, delo 38. 
12. März 1846 an Adlerberg richtete, ${ }^{51}$ geht hervor, dass der Zar Berlioz' Partitur als Geschenk angenommen hatte und dem Komponisten einen Ring schenken wollte. Gedeonov, der im Besitz des Drucks war, leitet diesen nun mit dem folgenden Begleitschreiben an das Hofministerium weiter:

„Gnädiger Herr, Vladimir Fedorovič!

Der Herr und Imperator, der die Ihrer Hoheit von dem berühmten Komponisten Hector Berlioz überreichte Fantastische Symphonie eigener Komposition seiner wohlwollenden Annahme für würdig befunden hat, geruhte allerhöchst zu befehlen: diese Symphonie an das Kaiserliche Hofministerium zu übergeben, den Schöpfer aber mit einem Ring im Wert von 300 Silberrubeln auszuzeichnen.

In Ausführung des Monarchenwillens übergebe ich hiermit Ihrer Hochwohlgeboren die erwähnte Symphonie und habe die Ehre hinzuzufügen, dass bezüglich des Geschenks für Herrn Berlioz bereits durch mich die entsprechende Anweisung an den Zuständigen erfolgt ist. Seien Sie, Gnädiger Herr, meiner vollkommenen Hochachtung und Ergebenheit versichert.

Gedeonov“52

Was ungewöhnlich an dem Vorgang erscheint, ist der handschriftliche Zusatz Adlerbergs auf dem oberen Briefrand, der mit dem 3. / 15. März datiert ist: „Ich befehle Allerhöchst, die Symphonie an den Herrn Theaterdirektor zu übergeben. "53 Vermutlich sollte die Partitur für Aufführungen bereitgehalten werden. Das zweite Dokument ist so der Begleitbrief, mit dem Adlerberg die Noten am 6. / 18. März 1846 wieder an Gedeonov in die Theaterdirektion zurücksandte:

„Gnädiger Herr Aleksandr Michajlovič.

Auf Allerhöchsten Befehl habe ich die Ehre, Ihrer Durchlaucht die Ihrer Hoheit von dem bekannten Komponisten Hector Berlioz überreichte und von ihm komponierte Fantastische Symphonie für die Kaiserlichen Theater zu übersenden. Ich bitte untertänigst, mich über den Erhalt derselben in Kenntnis zu setzen.

Seien Sie meiner vollkommenen Hochachtung und Ergebenheit versichert

V. Adlerberg" 54

Das dritte Dokument der Akte besteht schließlich in der Antwort des Theaterdirektors Gedeonov, der Adlerberg am 12. / 24. März 1846 über den richtigen Erhalt der Symphonie informierte:

51 Hier und im Folgenden werden Ereignisse in Russland doppelt nach dem julianischen und gregorianischen Kalender datiert.

52 „Милостивый Государь, Владимир Федорович! Государь Император, удостоив благосклонногопринятия поднесеннуюЕгоВеличеству известным Композитором Гектором Берлио Фантастическую симфонию его сочинения, высочайше повелеть изволил: передать эту симфонию в Министерство Императорского Двора, а сочинителю пожаловать перстень в триста рублей серебром. Во исполнение Монаршей воли, препровождая при сем к Вашему Высокопревосходительству помянутую симфонию, имею честь присовокупить, что о подарке для Г. Берлио сделано уже мною, к кому следует, надлежащее отношение. Примите, Милостивый Государь, уверение в совершенном моем почтении и преданности. [Подпись Гедеонов]. №1638. Февраля 28 дня 1846. года. Его Высокопревосходительству В. Ф. Адлербергу.“

53 „Высочайше повелеваю симфонию передать Г. Директору Театров.“

54 „Милостивый Государь Александр Михайлович. По Высочайшему повелению имею честь препроводить к Вашему Превосходительству, для Императорских театров, поднесенную Его Величеству известным композитором Гектором Берлио Фантастическую Симфонию 
„Gnädiger Herr Vladimir Fedorovič,

die auf Allerhöchsten Befehl und aufgrund der Nachricht Nr. 387 Eurer Hochwohlgeboren vom 6. dieses Märzes an die Kaiserlichen Theater geschickte, seiner Hoheit durch den Komponisten Hector Berlioz überreichte und von ihm komponierte Fantastische Symphonie habe ich erhalten - worüber ich Euer Hochwohlgeboren zu unterrichten die Ehre habe. Ich bitte Sie, sich meiner vollkommenen Hochachtung und Ergebenheit sicher zu sein." 55

So formvollendet der Versand der Partitur sich präsentiert - nahtlos dokumentiert von der russischen Hofbürokratie -, ist das Widmungsexemplar der Symphonie fantastique selbst leider bislang nicht von uns entdeckt worden.

Für die Chronologie aufschlussreich ist der hier beschriebene Vorgang, weil nun bekannt ist, dass die Symphonie fantastique das russische Hofministerium vor dem 28. Februar / 12. März 1846 erreichte. Dies legt den Schluss nahe, dass Berlioz sein Widmungsexemplar von unterwegs aus nach Russland schickte. Zumindest lässt der Umstand, dass zwischen der Anordnung des Zaren vom 12. März neuen Stils, Berlioz ein Präsent zu senden, und der Ankunft des Rings in Prag, spätestens am 16. April, nicht viel mehr als ein Monat verging, vermuten, dass auch die Reaktion des Zaren auf den Erhalt der Partitur zügig erfolgte. Dies würde bedeuten, dass Berlioz sein Widmungsexemplar vielleicht erst im Februar 1846 nach Petersburg sandte. Möglicherweise hatte er bis dahin vorgehabt, das Werk persönlich zu überreichen, und übergab es erst der Post, als die vielen Konzerteinladungen nach Prag, Breslau, Pest und Braunschweig die Fortsetzung seiner Reise nach Russland zur Fastenzeit 1846 undurchführbar werden ließen.

Die Russlandreise des Jahres 1847 greift das unterbrochene Projekt umgehend wieder auf. Man liest in der Regel, Berlioz habe seine Fahrt Anfang Januar 1847 in Angriff genommen. ${ }^{56}$ Neue Dokumente, die im 2003 erschienenen Supplément der Correspondance générale zugänglich geworden sind, zeigen inzwischen, dass die Planungen bereits Mitte Dezember 1846 begannen. So bat der Komponist den Kritiker Joseph-Esprit Duchesne, ihn als Rezensenten zu vertreten. ${ }^{57}$ Rechtzeitig eingeleitet hatte Berlioz auch die deutsche Übersetzung von La damnation de Faust, die er für Russland brauchte. ${ }^{58}$ Wie sein Brief an den Übersetzer, Vinzent Otto Nolte, zeigt, erwartete man ihn zur Fastenzeit, Mitte Februar. Es hatte demnach genaue Absprachen mit russischen Instanzen gegeben. An wen aber hatte Berlioz sich gewandt?

его сочинения, покорнейше прошу о получении оной меня уведомить. Примите уверения в совершенном моем почтении и преданности. Подписано В. Адлерберг. № 387. 6 марта 1846. Его Прев. А.М. Гедеонову.“

55 „12 Марта 1846. №85. Его Высокопревосходительству В.Ф. Адлербергу. Милостивый Государь Владимир Федорович, Присланная по Высочайшему повелению, при почтеннейшем отношении Вашего Высокопревосходительства от 6-го ч. сего Марта за №387-м для Императорских Театров, поднесенная Его Величеству композитором Гектором Берлио, Фантастическая симфония его сочинения, мною получена. - О чем имея честь Ваше Высокопревосходительство уведомить, прошу принять уверение в моем совершенном почтении и преданности. [Подпись: Александр Гедеонов].“

56 Vgl. die Chronologie für 1847, CG 3, S. 395: „Janvier: Préparation d'une tournée en Russie.“

57 Vgl. den Brief an Joseph-Esprit Duchesne, Paris, ca. 15.12.1846, CG 8, S. 267, Nr. 1085bis.

58 Vgl. den Brief an Vincent Otto Nolte, Paris, 3.1.1847, CG 8, S. 268, Nr. 1089bis. 


\section{Berlioz' russische Netzwerke}

Die bisherige Forschung über Berlioz und Russland hat sich vornehmlich auf die Bezüge des französischen Musikers zu russischen Künstlern konzentriert. Neben Michail Glinka geriet schon früh der Schriftsteller Vladimir Odoevskij mit seinen Musikfeuilletons in den Fokus des Interesses, zwei Gestalten, die in der russischen Kulturgeschichte Rang und Namen haben. Für Berlioz standen diese beiden Personen weniger im Vordergrund. Odoevskij spielt in seiner Korrespondenz nur einmal eine Rolle: in seiner Eigenschaft als Musikkritiker, der den französischen Komponisten um Informationen zu seinem bevorstehenden Petersburger Konzert gebeten hatte. ${ }^{59}$ Ein wenig anders sieht es mit Glinka aus. Nach einer ersten, flüchtigen Begegnung zwischen Glinka und Berlioz, die 1831 im Haus von Horace Vernet während Glinkas etwa zweiwöchigem Romaufenthalt stattfand, ${ }^{60}$ verkehrten die beiden Komponisten in den ersten Monaten des Jahres 1845 in Paris intensiver miteinander. Aus dieser zufällig zustande gekommenen Phase persönlicher Kommunikation hat sich auch der einzige bekannte Brief erhalten, den Berlioz an Glinka gerichtet hat. Berlioz bat darin um „quelques notes sur vous, sur vos premières études, sur les institutions musicales de la Russie, sur vos ouvrages“, um den Lesern des Journal des Débats „une idée approximative de votre haute supériorité" geben zu können. ${ }^{61}$

In der russischen Tradition wurde diesem Schreiben von Anfang an ein sehr hoher symbolischer Stellenwert beigemessen, an dem sich ablesen lässt, welches Prestige Berlioz in seiner Eigenschaft als Komponist und Musikkritiker bereits zu diesem Zeitpunkt besaß. ${ }^{62}$ Glinka selbst berichtete über seinen Kontakt zu Berlioz umgehend nach Russland und schickte den kostbaren Brief an Nikolaj Ivanovič Greč, den Herausgeber der Zeitschrift Severnaja pčela. ${ }^{63}$ Bereits am 18. April 1845 konnte Glinka seinem Freund Nestor Kukol'nik mitteilen: „Greč wird der Severnaja pčela eine kurze Beschreibung meines [Pariser] Konzerts zukommen lassen mit der Übersetzung und dem Originaltext des Berliozschen Briefs, den Berlioz mir zwei Wochen vor dem Konzert geschrieben hat und der als Beweis für die Aufrichtigkeit seiner Meinung über mich gelten kann. "64

59 Vgl. den Brief an Odoevskij, Sankt Petersburg, Februar 1847, CG 8, S. 269. Odoevskijs Berlioz gewidmete Besprechungen sind mittlerweile auch in englischer Übersetzung greifbar (vgl. The musical voyager, S. 302f.) und werden bei Dolenko, S. 119, als wichtige russische Rezeptionszeugnisse besprochen.

60 Die Information beruht auf Berlioz' Bericht in seinem Feuilleton über Glinka. Glinka erwähnt die Begegnung nicht in seinen Memoiren. Er vermerkte lediglich am Rande seines Manuskripts den Namen „Horace Vernet“, vgl. Michail Glinka, Literaturnye proizvedenija i perepiska, Bd. 1, Moskau 1973, S. 249.

61 Brief vom 25.3.1845, CG 3, S. 237.

62 Das Autograph dieses Briefs ist verschollen, vgl. CG 3, S. 238. Ausgiebig erläutert wird die Quellengeschichte in Glinka, Literaturnye proizvedenija i perepiska, Bd. 2b, Moskau 1977, S. $310 f$.

63 Vgl. Glinkas Brief an P.A. Barteneva, Paris, 21.5.1845, Glinka, Literaturnye proizvedenija i perepiska, Bd. 2a, S. 217.

64 „Греч сообщит в Северную пчелу краткое описание моего концерта с переводом и подлинником письма Берлиоза, написанного мне за две недели до концерта, которое может служить доказательством искренности его мнения обо мне." Brief an Nestor Kukol'nik, Paris, 18.4.1845, ebd., S. 209. 
Unter dem Titel Pariser Briefe (Parižskie pisłma) erschien der angekündigte Bericht samt dem Brief des berühmten Franzosen an seinen russischen Kollegen am 24. April / 6. Mai 1845. ${ }^{65}$ Wenige Tage später wurde auch Berlioz' Feuilleton über Glinka auf Russisch mit der folgenden Erläuterung veröffentlicht:

„In einer der letzten Nummern des Journal des Débats ist unter der Überschrift Michel de Glinka ein Artikel von Berlioz erschienen. Wir teilen ihn unseren Lesern so mit, wie er ist, ohne irgendwelche Änderungen oder Kommentare bezüglich der Fehler des Autors: es geht hier nicht um die Biographie M. I. Glinkas, sondern um die Meinung des berühmten Musikers und Kritikers zu unserem russischen Komponisten." 66

Damit wurde der Grundstein gelegt für den in der russischen Musikhistoriographie üblichen Verweis auf Berlioz' großes Engagement für Glinka. ${ }^{67}$

Für Berlioz dürfte der Kontakt zu Glinka indessen nur episodischen Wert besessen haben. Einen viel intensiveren, langjährigen Briefwechsel unterhielt er mit Aleksej L'vov, einer Gestalt, die in der russischen Musikwissenschaft des 20. Jahrhunderts aufgrund ihrer engen Bindung an den Zarenhof so gut wie gänzlich vernachlässigt worden ist. Außerdem besaß Berlioz Zugang zu anderen Personengruppen, die ihm bei seiner Russlandtournee von Nutzen sein konnten. Die Rekonstruktion solcher sozialen Netzwerke, die oft maßgeblich für den Transfer kultureller Güter verantwortlich sind, findet in der historisch ausgerichteten Musikwissenschaft in letzter Zeit stärkere Beachtung. ${ }^{68}$ Das Licht fällt in unserem Fall auf Angehörige sozialer Gruppen, wie sie in der sowjetischen Geschichtsforschung grundsätzlich stigmatisiert waren. ${ }^{69}$ Dies gilt zum einen für ausländische Musiker, die in Russland tätig waren, zum anderen für Mitglieder des Adels, des Zarenhauses und der an den Hof gebundenen Institutionen wie der Direktion der Kaiserlichen Theater oder der Hofsängerkapelle, der Aleksej L'vov vorstand.

Eine ganze Gruppe von Musikern, die sich in Russland früh für die Propaganda von Berlioz' Werken einsetzten, waren Deutsche. Bereits ein Jahr vor der bekannten Aufführung des Requiems gab es zum ersten Mal in Petersburg eine Komposition des französischen $\mathrm{Mu}-$ sikers zu hören, der in der Presse bis dahin vor allem in seiner Eigenschaft als Musikkritiker

65 Severnaja pčela, 24.4.1845, Nr. 90, S. 358f. Berlioz’ Brief ist in russischer Übersetzung in den Text inkorporiert (S. 358). In einer Anmerkung findet man außerdem den originalen französischen Wortlaut (S. 359). Dies ist also die Erstpublikation der verschollenen Quelle.

66 „В одном из последних нумеров Jornal des Débats помещена статья берлиоза (berlioz) [sic] под заглавием Michel de Glinka. Сообщаем ее нашим читателям как она есть без всяких перемен и замечаний на ошибки автора: дело здесь не в биографии М.И. Глинки, а в мнении знаменитого музыканта и критика о нашем русском композиторе." Sankt Peterburgskie vedomosti, 19.4.1845, Nr. 85, S. 385. Der Artikel erschien in Fortsetzung am 20.4.1845, Nr. 86, S. 389.

67 Vgl. Vladimir Stasov, „Pamjati M. I. Glinki, po slučaju 50-letiju jubileja ,Žizni za carja“", in: ders., Izbrannye stati o M. I. Glinke, Moskau 1955, S. 166-168; „Portret Glinki, delannyj v Pariže“, ebd., S. 210-212.

68 Zur Anwendung kommt die Netzwerk-Theorie in unterschiedlichen Bereichen der Musikwissenschaft, vgl. etwa Michael Custodis' Studie Die soziale Isolation der neuen Musik. Zum Kölner Musikleben nach 1945, Stuttgart 2004, den Sammelband Oper im Wandel der Gesellschaft. Kulturtransfers und Netzwerke des Musiktheaters in Europa, hrsg. von Philipp Ther u.a., Wien 2010, oder Benjamin Piekuts Aufsatz „Actor-Networks in Music-History: Clarifications and Critiques“, in: Twentieth-Century Music 11 (2014), S. 191-215.

69 Vgl. dagegen entsprechende Forschungen in den Archives Nationales von Peter Bloom, „Berlioz and Officialdom: Unpublished Correspondence“, in: 19 $9^{\text {th }}$ Century Music 4 (1980), S. 134-146. 
wahrgenommen worden war. Bei der Ankündigung des Konzerts wurde auf diesen Umstand eigens hingewiesen:

„Wir sind besonders neugierig, ein Werk von Berlioz kennen zu lernen, weil ihm in der Musikkritik in Paris keiner ebenbürtig ist. Seine Ansichten sind zuverlässig, und wenn die Schöpferkraft seiner Seele nicht hinter seinem kritischen Verstand zurücksteht, werden wir zweifellos in Berlioz' Werken viele originelle Schönheiten finden." ${ }^{\text {"V0 }}$

Das Konzert fand am 7. / 19. März 1840 im Engelhardt-Saal in Sankt Petersburg statt. Für welches Werk man sich entschieden hatte, ist nicht genau bekannt. Die Besprechungen nennen lediglich als Titel „Ouvertüre“. Vermutlich handelte es sich um die Ouvertüre zu Les Franc-juges (1826), die 1837 aus dem Manuskript von Robert Schumann in Leipzig aufgeführt und in Deutschland zum häufigsten Repertoirewerk der frühen Berlioz-Rezeption geworden war. ${ }^{71}$ Denn initiiert hatte das Petersburger Konzert der Cellovirtuose Johann Benjamin Groß, der in seinen Leipziger Jahren (1829-1833) in engem Kontakt zu Schumann gestanden hatte und auch später noch einen Briefwechsel mit ihm unterhielt. ${ }^{72}$

Ein anderer Deutscher, der sich Verdienste um die Propaganda für Berlioz erwarb, war Heinrich Romberg. Unter seiner Leitung fand am 1. / 13. März 1841 die russische Erstaufführung der Grande Messe des morts op. 5 statt. Nach der Pariser Uraufführung vom 5. Dezember 1837 konnte damit im Zarenreich die zweite komplette Aufführung dieses monumentalen Werks verwirklicht werden. Auf seiner Deutschlandreise (1843), in Marseille (1845) und Paris (1846) gelang es Berlioz dagegen nur einzelne Sätze zur Aufführung zu bringen. ${ }^{73}$ Als einzige Quelle über das Petersburger Konzert diente in der Berlioz-Literatur lange Zeit der vom 30. Juni 1841 datierende Bericht des Petersburger Korrespondenten J. Guillou, der am 18. Juli 1841 in der Revue et gazette musicale erschienen war. ${ }^{74}$ Aufgrund dieser Information hatte man als Aufführungstermin den Juni 1841 vermutet, ein ungewöhnliches Datum für ein Chorkonzert, wie man es eher in der Fastenzeit, der traditionellen russischen Konzertsaison, erwarten würde. ${ }^{75}$ Nur implizit liefert Elena Dolenko in ihrem

70 „Нам очень любопытно услышать сочинение Берлиоза, тем более, что он в музыкальной критике, не имеет соперников в Париже. Взгляд его верен, и если творческая способность его души не отстала от его критического ума, то, без сомнения, в сочинениях Берлиоза мы найдем много красот оригинальных.“ (Severnaja pčela, 7.3.1840, Nr. 53, S. 209).

71 Vgl. Arnold Jacobshagen, „Die Anfänge der deutschen Berlioz-Kritik“, in: Hector Berlioz. Ein Franzose in Deutschland, hrsg. von Matthias Brzoska u.a., Laaber 2005, S. 158f., 164.

72 Vgl. Bernhard R. Appel, „Johann Benjamin Groß (1809-1848). Anmerkungen zu Leben und Werk“, in: Robert Schumann, das Violoncello und die Cellisten seiner Zeit, hrsg. von Bernhard R. Appel und Matthias Wendt, Mainz 2007, S. 225f.; Galina Petrova, „Iogann Ben’jamin Gross - violončelist-virtuoz, zabytyj kompozitor“, in: Muzykal'nyj Peterburg. Enciklopedičeskij slovar'-issledovanie, Bd. 14: XIX vek. 1801-1861. Materialy k enciklopedii, hrsg. von N. A. Ogarkova, Sankt Petersburg [im Druck].

73 Vgl. Hector Berlioz, Grande messe des morts, hrsg. von Jürgen Kindermann, Kassel u.a. 1978 (NBE 9), S. IX.

74 J. Guillou, „Lettres sur la Russie“, in: Revue et gazette musicale, 18.7.1841, Nr. 42, S. 343-346. Gekürzt erschien der Bericht auch in: Journal des débats, 19.7.1841, S. 4. Guillou war offenbar ein Berlioz-Verehrer, den dieser in Petersburg dann auch persönlich kennenlernte. Im Brief an Dominique Tajan-Rogé, London, 10.11.1847 (CG 3, S. 462) bezeichnet Berlioz ihn als „véritable artiste, cordial, intelligent, dévoué, dont je suis si heureux d'avoir fait la connaissance".

75 „A complete performance was given in St. Petersburg in 1841 (probably in June) under Heinrich Romberg." NBE 9, S. IX. Die Angabe Juni 1841 findet sich auch unter dem Eintrag zu Romberg auf der Berlioz-Website: <http://www.hberlioz.com/Russia/russiafriends.htm\#romberg>, 24.4.2016. 
Aufsatz über die Berlioz-Rezeption in Russland das korrekte Datum, ${ }^{76}$ wie man es in zahlreichen Pressemitteilungen der Zeit finden kann. ${ }^{77}$ Von Interesse ist auch die ausführliche Ankündigung in der deutschsprachigen Sankt Petersburger Zeitung, die die verbreitete Deutung von Berlioz als Beethoven-Nachfolger weiterschreibt und daneben über den organisatorischen und finanziellen Aufwand berichtet, den Romberg betreiben musste, um die 150 Sänger aus dem Chor der Deutschen und der Russischen Oper sowie ein hundertköpfiges Orchester aufzustellen, zwei Monate zu proben und das Stimmmaterial kopieren zu lassen. ${ }^{78}$

Selbstverständlich gab es auch Franzosen, die im Petersburger Kulturbetrieb präsent waren. Berlioz erfuhr so von dem Konzert sowohl aus den französischen Zeitungen, als auch durch mündliche Berichte, wie er seiner Schwester Nanci Pal schrieb: „J'ai eu des détails ces

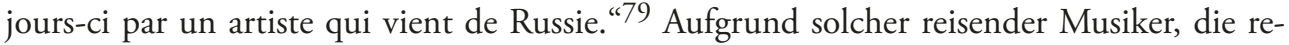
gelmäßig Brücken zwischen den großen europäischen Metropolen bauten, verfügte Berlioz über interne Informationen wie die Angaben zu den Kosten der Aufführung und zum Gewinn, den Romberg dank der Spendenwilligkeit des russischen Adels erzielt hatte. ${ }^{80} \mathrm{Ganz}$ offensichtlich weckte dieses Ereignis Berlioz' Interesse an Russland und seinen gewaltigen musikalischen wie finanziellen Ressourcen. Man findet so in seiner Korrespondenz bereits in diesem Zusammenhang den Gedanken formuliert, eine Konzertreise nach Russland zu unternehmen: „si j’allais en Russie à présent je serais bien reçu. “ ${ }^{11}$ Die sich daran anschließende Zeile gar erweckt den Eindruck, Berlioz habe diesen Plan schon länger in Erwägung gezogen.

Romberg begründete mit seiner Initiative so etwas wie eine eigenständige russische Berlioz-Tradition. Offenbar standen in Petersburg 1845 auf einem Wohltätigkeitskonzert mit Pauline Viardot erneut mehrere Sätze des Requiems auf dem Programm. Im Juni berichtete der Russlandkorrespondent der Revue et gazette musicale:

„On a exécuté [...] quatre numéros du Requiem de M. Berlioz, qui ont produit la plus profonde impression sur l'auditoire. Les instruments à cordes étaient cependant trop faibles comparativement à la masse de ceux de cuivre. Les deux cents choristes ont bravement chanté, surtout dans le Dies irae et le Lacrymosa. On est fort curieux ici d'entendre cet ouvrage et les symphonies de M. Berlioz exécutés sous sa direction." 82

In der Konzertchronologie im Anhang der Geschichte der russischen Musik wird eine Aufführung des Requiems auf den 6. / 18. April 1845 datiert. ${ }^{83}$ Die Zeitungsankündigungen dieses Konzerts erwähnen allerdings nur Auftritte Viardots und anderer Sänger der italienischen Opern. ${ }^{84}$ Von Berlioz' Chorwerk ist nirgends die Rede, so dass an der Richtigkeit dieses Datums Zweifel angebracht sind. ${ }^{85}$ In jedem Fall aber sollte das Requiem in Russland stets besondere Popularität genießen. Tief bewegt berichtete der Komponist 1868 über die Auf-

76 Vgl. Dolenko, „Hector Berlioz as Reflected in the Russian Press“, S. 119.

77 Vgl. etwa Russkij vestnik, 1841, Bd. 1, Nr. 3, S. 775.

78 Vgl. „Concert des Herrn Heinrich Romberg 1. März“, in: Sankt Petersburger Zeitung 23.2. / 7.3.1841, Nr. 43, S. 184.

79 Brief an Nanci Pal, Paris, zwischen dem 23. und 25.8.1841, CG 2, S. 693.

80 Vgl. die Details im Brief an Humbert Ferrand, Paris, 3.10.1841, CG 2, S. 700.

81 Brief an Nanci Pal, Paris, zwischen dem 23. und 25.8.1841, CG 2, S. 693.

82 Revue et gazette musicale, 8.6.1845, Nr. 23, S. 192.

83 Vgl. Istorija russkoj muzyki. Tom pjatyj: 1826 - 1850, hrsg. von Jurij Keldyš u.a., Moskau 1988, S. 504.

84 Vgl. Sankt Petersburger Zeitung, 7.-9.4.1845, Nr. 79, S. 144.

85 Durchgesehen wurde für diesen Beitrag die Rubrik „Konzerte“ der Zeitschriften Severnaja pčela, SanktPeterburgskie vedomosti und Sankt Petersburger Zeitung für die Monate März und April. 
führung in der Moskauer Manege, bei der über zehntausend Zuhörer ihn mit Ovationen gefeiert hatten. ${ }^{86}$

$\mathrm{Zu}$ den Deutschen, auf deren Vermittlungstätigkeit sich Berlioz stützen konnte, zählt ferner eine außerhalb Russlands gänzlich unbekannte Gestalt, nämlich der zweite Übersetzer des Librettos von La damnation de Faust, der sich in Petersburg daran machte, den von Vinzent Otto Nolte gelieferten Text zu revidieren. Bei der kompletten Aufführung des Werks am 3. / 15. März 1847 sangen zwar nicht alle Beteiligten in deutscher Sprache - für den Interpreten des Faust etwa, den italienischen Tenor Ricciardi, war der originale französische Text leichter zu bewältigen. Doch die in Russland bereitgestellte deutsche Fassung des Librettos ging in den Erstdruck ein: „[...] the work was done again by one Münzloff, probably a German living in Russia, whose translation is written into the autograph and appeared in the published score with his name spelt ,Minslaff. " 87

Im Westen unbekannt, findet man Münzloffs/Minslaffs Namen in allen großen biographischen Nachschlagewerken russischer Provenienz. ${ }^{88}$ Sein Name lautet in transliterierter Form Rudol'f (Robert) Ivanovič Minclov. Geboren am 18. (oder 11.) November 1811 in Königsberg, gestorben am 31. Oktober 1883 in Petersburg, wirkte Minclov nach einem Philosophiestudium in Königsberg zunächst als Deutschlehrer in Petersburg. Zur Zeit von Berlioz' Besuch arbeitete er am Mariinskij institut, einer Erziehungsanstalt für adlige Mädchen. Später wechselte er an andere Gymnasien und erteilte von 1856 bis 1860 dem Thronfolger Aleksandr Aleksandrovič und seinen Brüdern Deutschunterricht. Seit Oktober 1847 war Minclov zudem als Bibliothekar an der Petersburger Öffentlichen Bibliothek angestellt, wo er bis an sein Lebensende ein ihm angemessenes Wirkungsfeld fand. Er spezialisierte sich auf Inkunabeln und alte Drucke und richtete ein „Faustkabinett“ ein, in dem die Zimelien der Petersburger Sammlung ausgestellt waren. Sein teils deutsches, teils russisches Schriftenverzeichnis weist eine Vielzahl von Studien zur Bibliographie, Bestandskataloge, Fachaufsätze über Inkunabeln und Aldinen und auch einige Übersetzungen russischer literarischer Texte ins Deutsche auf. Unberücksichtigt geblieben ist in der Literatur über den Bibliographen dabei der Umstand, dass er auch das Libretto zu La damnation de Faust übertragen bzw. revidiert hat. Möglicherweise hatte man ihn als Kenner altdeutscher Kultur als besonders geeignet dafür gehalten.

Dass die deutsche Berlioz-Rezeption in mancherlei Hinsicht den Weg für die russische bereitete, gilt nicht nur für Musikerkreise. Zu Berlioz' deutschen Verehrern zählte König Friedrich Wilhelm IV. von Preußen. Von diesem erhielt der Komponist ein persönliches Empfehlungsschreiben an dessen Schwester Charlotte, die russische Zarin Aleksandra Fedorovna. ${ }^{89}$ Wie mittlerweile bekannt ist, unterstützte auch Alexander von Humboldt diese

86 Vgl. die Briefe aus Moskau, vom 10.1.1868, und aus Petersburg, vom 3. und 18.1.1868, CG 7 , S. 655-657, 660-662.

87 Hector Berlioz, La damnation de Faust, hrsg. von Julian Rushton, Kassel u.a. 1986 (NBE 8b), S. 458. Siehe die bibliographische Beschreibung des ersten Partiturdrucks, Paris: Richault 1854, ebd., S. 482.

88 Vgl. für die folgende Darstellung M. V. Maškova, Art. „Minclov, Rudol'f (Robert) Ivanovič“, in: Sotrudniki Rossijskoj nacional'noj biblioteki - dejateli nauki i kul'tury, Bd. 1: Imperatorskaja publičnaja biblioteka 1795-1917, Sankt Petersburg 1995, S. 361-363, <http://www.nlr.ru/nlr_history/persons/ info.php?id=114>, 24.4.2016.

89 Dieser von Cairns zitierte Brief wurde durch Julien Tiersot bekannt gemacht, vgl. Julien Tiersot, Lettres de musiciens écrites en Français du XVe au XIX siècle (de 1831 à 1885), Paris / Mailand 1936, S. 209. Leider hat er die Quelle ohne Herkunftsbeleg publiziert, was eine Suche nach dem erwähnten ausführlichen ersten Brief des Königs an seine Schwester erschwert. 
Angelegenheit. ${ }^{90}$ Während Nikolaj I. aus gesundheitlichen Gründen nicht an Berlioz' Petersburger Konzerten teilnahm, ließ sich Aleksandra Fedorovna offenbar von den Lobesworten ihres Bruders positiv beeinflussen. So zumindest erklärte Berlioz ihr Interesse: „Le Roi de Prusse avait eu la bonté d'écrire à sa sœur l'Impératrice de Russie à mon sujet et je dois sans doute beaucoup à sa chaleureuse recommendation. "91 In mehreren Briefen schilderte er die enthusiastische Aufnahme, die er durch die Zarin erfuhr:

„L'Impératrice qui n’avait pas mis le pied au concert depuis des années est venue à ma première soirée; elle m’a fait demander après la première partie de Faust, et j’ai reçu dans sa loge toute une ode en prose de compliments de sa part et de celle de ses fils les grands-ducs Alexandre et Constantin; puis le lendemain les bagues en diamants et les épingles sont venues solidifier toutes ces brillantes phrases."

Ein Dokument aus der offiziellen Hofbürokratie, das illustriert, über welche Kanäle die erwähnten Kostbarkeiten in die Hände des Komponisten gelangten, befindet sich im RGIA:

„Auf allerhöchsten Befehl schlage ich dem Kabinett vor, dem Herrn Direktor der Kaiserlichen Theater ein Geschenk von dreihundert Silberrubeln auszuliefern, das Herrn Berlioz höchstgnädiglich für den Besuch seines am 3. dieses Monats stattgefundenen Konzerts durch Ihre Hohheit die Herrscherin gewährt worden ist.

Der Minister des Kaiserlichen Hofes Fürst Volkonskij. “93

Mit dieser Quelle berühren wir den großen Bereich der höfischen Institutionen, auf deren Unterstützung Berlioz angewiesen war. Neben dem Hofminister, Fürst Volkonskij, der im Auftrag der Zarin die Anweisung gab, ein Präsent aus der Kaiserlichen Privatschatulle auszuwählen, tritt als weiterer Akteur der Direktor der Kaiserlichen Theater, Aleksandr Gedeonov, in Erscheinung. Er sollte das Geschenk, vermutlich kein Bargeld, sondern ein Schmuckstück, in Empfang nehmen, um es dann Berlioz persönlich zu überreichen. Dass Gedeonov für Berlioz spätestens seit der Übersendung der Widmungspartitur der Symphonie fantastique eine Schlüsselgestalt in der Petersburger Hofbürokratie war, liegt auf der Hand. In seinem Brief vom 28. Januar 1847 an Heinrich Wilhelm Ernst, der zur gleichen Zeit eine Russlandreise plante, nennt Berlioz den Theaterdirektor gemeinsam mit zwei weiteren Gestalten, die ihm bei der Organisation vor Ort helfen sollten:

„Maintenant sachez que nous allons nous retrouver à St Pétersbourg, je fais comme vous ce grand voyage tant de fois projeté, tant de fois remis. J'ai écrit au comte Wielhorski, au général Lwoff et à $M$.

90 Vgl. Humboldts Brief an Berlioz, Berlin, 27.2.1847, Eberhard Knobloch / Ingo Schwarz, „Alexander von Humboldt und Hector Berlioz", in: Alexander von Humboldt im Netz IV, 7 (2003), <https://www. uni-potsdam.de/romanistik/hin/hin7/knobloch-schwarz.htm>, 24.4.2016.

91 Brief an Louis Berlioz, Petersburg, 19./31.3.1847, CG 3, S. 412.

92 Brief an Léon Escudier, Moskau, 24.3./5.4.1847, CG 3, S. 415. Vgl. auch die Briefe an Auguste Morel, Petersburg, 19./31.3.1847, CG 3, S. 413f., sowie an Adèle Suat, Petersburg, 25.4./7.5.1847, CG 3, S. 422.

93 „По высочайшему повелению, предлагаю кабинету доставить к Г-ну Директору Императорских театров подарок в триста рублей серебром, Всемилостивейше пожалованный Г-ну Берлиозу, за посещение Ея Величеством Государынею концерта его, бывшего 3 сего месяца. Министр Императорского Двора Князь Волконский.“ „Vysočajšie povelenija: Ministerstvo Imperatorskogo Dvora ot 5 marta 1847 Nr. 730 O podarke G. Berliozu“, RGIA, fond 486, opis' 5 , Nr. 177, folio 72. 
Gévéonof [sic] pour les prévenir de mon arrivée et obtenir trois jours pour mes concerts pendant le Carême." 94

Keiner der drei nach Russland geschickten Briefe ist bisher gefunden worden. Gibt es für das Schreiben an Wielhorski zumindest einen Anhaltspunkt, ${ }^{95}$ so harrt die Korrespondenz mit Gedeonov noch ihrer Entdeckung. Lediglich auf jenen Brief, in dem der französische Komponist L'vov über seine baldige Ankunft in Petersburg informierte, hat sich ein indirekter Hinweis erhalten. Denn die Zeitung Severnaja pčela teilte ihren Lesern die Neuigkeit umgehend mit:

„Man hat uns zum Lesen einen am 13. (25.) Januar 1847 in Paris von dem berühmten Hector Berlioz abgefassten Brief vorgelegt, in dem er dem ersten russischen Komponisten und Interpreten, der europäischen Ruhm erlangt hat, seiner Exzellenz Aleksej Fedorovič L'vov, mitteilt, er werde Ende Februar unverzüglich nach Petersburg kommen und hier mit Hilfe der hiesigen Virtuosen und Sänger einige seiner Kompositionen aufführen..."96

Zwischen L'vov und Berlioz gab es zu diesem Zeitpunkt schon einen längeren Briefwechsel. Nicht nur der früheste bekannte Brief des Franzosen vom 1. August 1845 stellt bereits das Antwortschreiben auf eine Anfrage des Russen dar. L'vov war 1837 Leiter der Kaiserlichen Hofsängerkapelle geworden. In dieser offiziellen Eigenschaft scheint er sich erstmals 1843 an den französischen Komponisten gewandt zu haben, wie sich indirekt aus einer oft erwähnten, aber nie inhaltlich ausgewerteten Quelle erschließen lässt. In der Revue et gazette musicale ließ Berlioz im August des Jahres folgende Notiz publizieren:

„L’empereur de Russie vient de faire écrire à M. Hector Berlioz, par le chef de la chapelle de la musique impériale, dans le but de prier cet artiste d'arranger les plains-chants de l'Eglise grecque à seize parties en quadruple chœur. Les instructions adressées à M. Berlioz lui prescrivent d'employer dans chacun des chœurs les voix de contre-basses, assez communes parmi les chantres russes. "977

Der hier referierte Brief wirft ein interessantes Licht auf L'vovs Aktivitäten in der Sängerkapelle. Es ist bekannt, dass Zar Nikolaj sich persönlich für eine Reform des orthodoxen Kirchengesangs interessierte. ${ }^{98}$ Er strebte eine Vereinheitlichung der stark mündlich geprägten kirchenmusikalischen Praxis an - in ganz Russland sollte künftig die Musizierweise der Kaiserlichen Hofkapelle als Modell dienen. Die Gesänge selbst sollten nach westeuropäischen Mustern harmonisiert werden. Das Projekt, das vom Moskauer Metropoliten nicht gutgeheißen wurde, da die Hofkapelle im Laufe der Zeit eine eigene Sondertradition ausgebildet hatte, die zu stark von der ursprünglichen russisch-orthodoxen Liturgie abwich, scheint 1843 noch keine Früchte getragen zu haben. Dass es aber zu diesem Zeitpunkt überhaupt einen offiziellen Versuch gab, einen ausländischen Komponisten für das Projekt zu gewinnen, scheint in der Historiographie der russischen Kirchenmusik bislang nicht bekannt ge-

94 CG 3, Nr. 1095, S. 404.

95 Vgl. CG 3, S. 399f.

96 „Нам сообщили для прочтения письмо, года, писанное из Парижа 13-го (25-го) января 1847, знаменитым Гектором Берлиозом, в котором он извещает первого Русского композитора и исполнителя, приобретшего Европейскую славу Его Превосходительство Алексея Федоровича Львова, что он приедет непременно в Петербург, в конце февраля и намерен исполнить здесь, при помощи здешних виртуозов и певцов, несколько своих композиций... “ Severnaja pčela, 29.1.1847, Nr. 23, S. 3.

97 Revue et gazette musciale, 13.8.1843, Nr. 33, S. 285; Nachdruck im Werkverzeichnis, S. 424.

98 Vgl. I. Gardner, Aleksej Fedorovič L'vov. Direktor Imperatorskoj pridvornoj pevčeskoj kapelly i duchovnyj kompozitor (1798 - 1870), Jordanville, N.Y., 1970, S. 45-51. 
wesen zu sein. Im August 1846 bat Nikolaj I. dann L’vov persönlich, eine mehrstimmige Fassung des Obichod zu erstellen. Zum Zeitpunkt von Berlioz' Russlandreise stand die Frage einer Beteiligung des Franzosen an der Chorbearbeitung damit vermutlich auch nicht mehr im Raum.

Wie L’vov 1843 auf Berlioz aufmerksam geworden war, lässt sich leider nicht sagen. Auf der großen Tournee, die er 1840 als Violinvirtuose durch Europa unternommen hatte, scheint er den französischen Komponisten nicht persönlich kennengelernt zu haben. Wie er in seinen Aufzeichnungen festhielt, traf er sich in Berlin „mit [seinem] Lehrer und Freund Spontini“99. Dort lernte er auch den „klugen Meyerbeer“ („с умным Мейербером“), in Leipzig Mendelssohn, in London Moscheles und in Paris Cherubini, sowie den „berühmten Dirigenten“ („со знаменитым дирижером“) der Concerts du Conservatoire, Habeneck, kennen, welchen er als „Abiek“ („Абиек“) bezeichnet. ${ }^{100}$ Der Name Berlioz taucht dabei nicht auf.

Berlioz seinerseits erwähnt L'vov erstmals in seinem Glinka gewidmeten Feuilleton vom 16. April 1845. Nachdem er geschildert hat, wie Glinka in den „terres à demi sauvages"101 der Ukraine nach Naturtalenten für den Chor der Kaiserlichen Sängerkapelle suchte, geht er auf dessen Nachfolger ein, den aktuellen Inhaber des Direktorenpostens:

\footnotetext{
„Au bout de trois ou quatre ans, Glinka voyant sa santé chanceler, se décida à abandonner la direction des chantres de la cour, et à quitter de nouveau la Russie. Néanmoins cette chapelle, qu'il laissa dans un admirable état de splendeur, a gagné encore dans ces derniers temps sous la savante direction du général Lwoff, violoniste et compositeur d'un grand mérite, un des amateurs, on pourrait dire, un des artistes les plus distingués que possède la Russie, et dont j’ai souvent entendu louer les œuvres pendant mon séjour à Berlin. “102
}

Die Formulierung legt es nahe, dass die beiden sich nicht persönlich begegnet waren. Stattdessen bezieht sich Berlioz auf Informationen, die er in Berlin über L'vov erhalten hatte. Der aus altem Rurikidenadel stammende Fürst, Adjutant des Zaren, war als Autor der Zarenhymne in Europa eine Berühmtheit. Namentlich in Deutschland profitierte er von der politischen Allianz und den engen dynastischen Beziehungen zum Zarenreich und wurde als musikalischer Sachwalter Nikolajs I. wahrgenommen. Aufschlussreich für die damalige kulturpolitische Atmosphäre ist L'vovs Bericht über eine Soiree während seiner Deutschlandreise, auf der die Hymne „Gott, schütze den Zaren“ (in deutscher Übersetzung) aufgeführt wurde. Folgendermaßen schilderte der Komponist die exaltierte Reaktion der Anwesenden: „[...] Klatschen, Stampfen mit Füßen und Stühlen, Schreie. Ich musste wiederholen; dieselbe Begeisterung, dieselben Schreie vivat Nicolas!“103

L'vovs Verhältnis zu Berlioz bedarf noch einer gründlicheren Erforschung. ${ }^{104}$ Voraussetzung dafür wäre jedoch eine intensivere Beschäftigung mit dem russischen Musiker, zu dem

99 „[...] с учителем и другом Спонтини.“ „Zapiski A. F. L’vova“, in: Russkij archiv, 1884, Nr. 5, S. 67. 100 Ebd., S. 68.

101 Hector Berlioz, „Michel de Glinka“, in: Journal des débats politiques et littéraires, 16.4.1845, S. 1.

102 Ebd.

103 „Рукоплескания, стук ногами и стульями, крики. Я должен был повторить; тот же восторг, те же крики vivat Nicolas!“ Ebd., S. 75.

104 Wie stark man L'vov vernachlässigt hat, erweist sich auch an dem Umstand, dass von einer ganzen Reihe noch im 19. Jahrhundert publizierter Briefe, die Berlioz an L'vov gerichtet hatte, die Autographe heute unbekannt sind, vgl. die Quellenangaben zu den Briefen CG 1112, 1170, 1246, 1379, 1443. 
bislang nur wenige Arbeiten vorliegen. ${ }^{105}$ Sowohl seine kirchenmusikalischen Aktivitäten als auch seine kompositorischen Versuche auf dem Gebiet der Oper sind so gut wie unerforscht. $\mathrm{Zu}$ rekonstruieren wären überdies L'vovs Bestrebungen, das russische Musikleben zu reformieren, die an verschiedenen Intrigen - unter anderem bestanden Rivalitäten zwischen L'vov, Gedeonov und Volkonskij - scheiterten. Berlioz wurde dabei von L'vov offenbar immer wieder als mögliche Figur gesehen, die er nach Petersburg holen wollte in der Hoffnung, aus der russischen Hauptstadt „le centre du monde musical“ zu machen. ${ }^{106}$

Neben den ausländischen Musikern in Russland einerseits und den Angehörigen des Zarenhofs andererseits muss noch eine weitere Gruppe in ihrer Rolle als Vermittler eines grenzüberschreitenden Kulturtransfers Berücksichtigung finden, nämlich die russischen Aristokraten, die sich in Westeuropa aufhielten. Auch Berlioz konnte sich in seinem unmittelbaren Wirkungsfeld in Paris zweifellos Zutritt zu russischen Milieus verschaffen. In seinem Brief an L'vov vom 1. August 1845 erwähnte Berlioz so „quelques autres personnes qui connaissent fort bien les mœurs musicales de Russie“. ${ }^{107}$ Es ist nicht ganz einfach, diesen Bereich der Alltagskultur greifbar zu machen. Als eine Quelle, die einige hilfreiche Informationen für das uns interessierende Jahr 1844/45 enthält, bietet sich Michail Glinkas publiziert vorliegender schriftlicher Nachlass an. Dass Glinka an der Planung von Berlioz' Russlandreise beteiligt war, hat der Franzose selbst angedeutet. Auch Glinka erwähnt diesen Aspekt in seinen Erinnerungen: „Ich besuchte oft Berlioz, seine Unterhaltungen waren höchst interessant, er sprach scharf und sogar böse (mordant); soweit wie möglich trug ich zum Erfolg seiner Reise nach Russland bei." 108

Ähnlich wie Berlioz' Brief an L'vov deutet auch diese Quelle mit ihrer vorsichtigen Formulierung darauf hin, dass Glinka nicht der einzige oder wichtigste Protagonist in der Russland-Angelegenheit war. Ganz offenkundig wurde er erst zu einem späten Zeitpunkt in die strategischen Überlegungen eingebunden. Glinka war bereits im Sommer 1844 in die französische Hauptstadt gekommen. Anfänglich führte er dort ein weitgehend isoliertes Leben. Sprach er im September 1844 im Brief an seine Mutter noch sehr vage von Plänen, mit Pariser Musikern bekannt zu werden, um mit deren Hilfe Aufführungen seiner Werke zu organisieren und in Frankreich als Musiker wahrgenommen zu werden, ${ }^{109}$ so konnte er am 23. Januar 1845 schließlich von gewissen Erfolgen berichten:

„Ich bin nun fast sechs Monate in Paris und beginne erst in dieser letzten Zeit Bekanntschaft mit Künstlern und anderen bemerkenswerten Personen zu machen. Das Leben wird angenehmer und

105 Ljubov“ Zolotnickaja, „A.F. L'vov“, in: Rossija - Evropa. Kontakty muzykal'nych kul'tur, hrsg. von Elena Chodorkovskaja, Sankt Petersburg 1994, S. 116-156; Aleksandra Savenko, „K istorii dialoga russkogo i evropejskogo iskusstva. A.F. L'vov", in: Nasledie XVIII - XIX veka. Sbornik statej, materialov i dokumentov, Bd. 2, hrsg. von P.E. Vajdman und E.V. Vlasova, Moskau 2013, S. 95-20.

106 Vgl. den Brief an L'vov, London, 29.1.1848, CG 3, S. 514.

107 CG 3, S. 270.

108 „Я часто навещал Берлиоза, его беседа была весьма занимательна, он говорил остро и даже зло (mordant); по возможности, я содействовал успешному его путешествию в Россию.“ Glinka, Literaturnye proizvedenija i perepiska, Bd. 1, S. 321.

109 Vgl. den Brief an Evgenija Glinka, Paris 28.9.1844, Glinka, Literaturnye proizvedenija i perepiska, Bd. 2a, S. 171. 
abwechslungsreicher, und überdies eröffnet sich gerade eine Gelegenheit, mit dem Pariser Publikum in Berührung zu kommen und es mit einigen meiner Werke bekannt zu machen. " ${ }^{110}$

Unterstützung hatte Glinka von der aus Paris stammenden, in Russland eingebürgerten Opernsängerin Aleksandra Solov'eva (geb. Verteuil) ${ }^{111}$ erhalten, die soeben aus Petersburg eingetroffen war. Sie sollte im Théâtre italien mit zwei Arien aus Glinkas Oper Žizn'za Carja (Ein Leben für den Zaren) auftreten. ${ }^{112}$ In den Wintermonaten fanden sich mehr und mehr andere russische Aristokraten in Paris ein, die Glinka aus seiner Passivität rissen:

„Im Winter reisten viele meiner bekannten Kompatrioten an. Unter ihnen war der Fürst Vasilij Petrovič Golicyn [...]. Er und andere Freunde und russische Damen überredeten mich, Paris mit meiner Musik bekannt zu machen, und aus Dummheit willigte ich ein. Als Souza, bei dem ich häufig war, von dieser Absicht erfuhr, bot er mir seine Dienste an. Er machte mich mit Hector Berlioz bekannt, der zu dieser Zeit über eine Reise nach Russland nachdachte, wobei er sich eine reiche Ernte nicht nur an Applaudissements, sondern auch an Geld erhoffte. Er ging außerordentlich freundlich mit mir um (was man vom Großteil der Pariser Künstler, die unerträglich hochmütig sind, nicht erwarten kann); ich besuchte ihn dreimal wöchentlich, sprach mit ihm offen über Musik und besonders über seine Werke, die mir gefielen, vor allem die im fantastischen Genre [...]." 113

Als konkreten Vermittler zu Berlioz nennt Glinka im Rückblick den spanischen Marquis A. de Souza, einen Musikliebhaber, den er bereits im Herbst kennengelernt hatte. ${ }^{114}$ Der Kontakt zu Souza war für Glinka interessant, weil sein vorrangiges Ziel in Paris die Vorbereitung einer Spanienreise war. Souza konnte ihm als Angehöriger der Spanischen Botschaft dabei behilflich sein. Besonders dankbar war ihm Glinka, als er ihm einen spanischen Sprachlehrer vermittelte. ${ }^{115}$ Leider konnte Marquis Souza, der sich auch in Glinkas Album eintrug, weder von russischen Forschern identifiziert werden, ${ }^{116}$ noch ist sein Name in der Berlioz-Biographik geläufig. Seine Vermittlung dürfte indessen nicht zielführend gewesen sein. Berlioz bekannte im August 1845 gegenüber L'vov, dass ihn Glinkas Werke, von diesem zunächst nur am Klavier vorgestellt, anfangs wenig begeisterten. ${ }^{117}$ Er sah sich erst veranlasst, Glinka

110 „Я в Париже без малого шесть месяцев и только в это последнее время начинаю приобретать знакомства с артистами и другими примечательными лицами. Жизнь для меня становится приятнее и разнообразнее, и, сверх того, открывается случай вступить в сношение с парижской публикой и познакомить ее с некоторыми из моих произведений.“ Ebd., S. 190f.

111 Vgl. Glinka, Literaturnye proizvedenija i perepiska, Bd. 1, S. 246.

112 Vgl. Glinka, Literaturnye proizvedenija i perepiska, Bd. 2a, S. 191.

113 „Зимой приехало много моих знакомых соотечественников. Между ними князь Василий Петрович Голицын [...]. Он и другие приятели и русские барыни уговорили меня познакомить Париж с моей музыкой, и я, по глупости, согласился на то. Souza, у которого я бывал часто, узнав об этом намерении, предложил мне свои услуги. Он познакомил меня с Гектором Берлиозом, который в то время помышлял о путешествии в Россию, надеясь на обильную жатву не одних рукоплесканий, но и денег. Он обошелся со мною чрезвычайно ласково (чего не добьешься от большей части парижских артистов, которые невыносимо надменны), - я посещал его раза по три в неделю, откровенно беседуя с ним о музыке, и особенно об его сочинениях, кои мне нравились, в особеннсоти в фантастическом роде [...]."Glinka, Literaturnye proizvedenija i perepiska, Bd. 1, S. $319 \mathrm{f}$.

114 Ebd., S. 318.

115 Vgl. Glinkas Brief an die Mutter, Paris, 16.11.1844, Glinka, Literaturnye proizvedenija i perepiska, Bd. 2a, S. 177.

116 Vgl. den Kommentar ebd., S. 402.

117 Vgl. CG 3, S. 271: „La même chose m’est arrivée avec M. de Glinka; j'étais fort loin, après avoir entendu jouer par lui sur le piano des fragments de ses opéras, d'en avoir l'opinion que j'en ai conçue plus tard en les faisant exécuter à mes concerts du cirque." 
stärker zu unterstützen, nachdem sich andere, einflussreichere Russen für diesen eingesetzt hatten. Wer die Fäden hinter den Kulissen gezogen hatte, schildert Glinka im schon zitierten Brief an seinen Schwager Victor Fleury nach Russland:

„La représentation extraordinaire aux Italiens n’est pas encore décidée, mais en revanche on va exécuter deux de mes moreceaux à la 3-me Fête musicale, donnée par Berlioz au cirque des Champs Elysées. [...] Faites part, je vous prie, de cette heureuse circonstance au comte de Vielhorsky et dites-lui de ma part que je dois cette faveur inattendue au prince Grégoire de Volkonsky qui m’a donné une lettre pour m-r Berlioz, afin qu'il lui dise combien je lui suis reconnaissant. "118

Die russische Fürstenfamilie Volkonskij war weit verzweigt. In Künstlerkreisen als Sängerin und Dichterin bekannt war etwa Zinaida Aleksandrovna Volkonskaja (1792-1862), die mit ihrem Sohn Aleksandr Nikitič Volkonskij (1811-1878) eben zu jener Zeit in Rom lebte, als auch Berlioz sich dort aufhielt. In einem seiner Briefe berichtet er über einen „bal masqué chez la princesse de Wolkonski“. ${ }^{119}$ Auch Glinka besuchte die Fürstin in dem von ihr bewohnten Palazzo Poli. ${ }^{120}$

Der im Brief an Fleury erwähnte Fürst Grigorij Petrovič Volkonskij (1808-1882) war dagegen ein Sohn des Hofministers Petr Michajlovič Volkonskij und gefiel sich in der Protektion russischer Musiker. ${ }^{121}$ Interessant erscheint der Umstand, dass er auch einen Ruf als begabter Sänger genoss und gelegentlich Opernrollen übernahm. ${ }^{122}$ Auch er befand sich zufällig 1831 in Rom, könnte demnach Berlioz begegnet sein. Diese Annahme erscheint umso plausibler, als in Berlioz' Korrespondenz ein isoliert stehender Brief vom 17. März 1837 überliefert ist, der an einen „Prince Woklonski“ gerichtet ist. ${ }^{123}$ Im Index wird diese Person als Aleksandr Nikitič Volkonskij identifiziert. ${ }^{124} \mathrm{Da}$ Berlioz seinen russischen Prinzen 1837 indessen bat, bei einer Probeaufführung des Benvenuto Cellini die Basspartie zu übernehmen, muss es sich um einen versierten Sänger gehandelt haben. Es liegt näher, Grigorij Volkonskij als Adressaten zu vermuten, der acht Jahre später dann als Vermittler von Glinkas Bekanntschaft mit Berlioz in Erscheinung treten sollte.

Unser Beitrag entwirft kein gänzlich neues Bild von Berlioz' Verhältnis zu Russland, auch wenn verschiedene Fakten erklärt, berichtigt oder neu ermittelt werden konnten. In einem weiteren Sinn aber sollte das Bewusstsein dafür geschärft werden, wie vielschichtig die Bezugsfelder waren, die den französischen Komponisten mit dem Zarenreich verbanden, und wie begrenzt der Zugang gewesen ist, mit dem man sich dem Thema bisher genähert hat. Als überfällig erscheint eine gründlichere Aufarbeitung der Berlioz-Rezeption in der russischen Presse. Deutlich geworden sein dürfte zudem der starke Quellenverlust im Bereich der Korrespondenz, der sich durch künftige intensive Recherchen vor allem in russischen Archiven

118 Paris 27.2.1845, Glinka, Literaturnye proizvedenija i perepiska, Bd. 2a, S. 194.

119 Brief an die Familie, Rom, 24. Juni 1831, CG 1, S. 460.

120 Glinka, Literaturnye proizvedenija i perepiska, Bd. 1, S. 249.

121 So führte auch der Tenor Ivanov auf seiner Italienreise ein Empfehlungsschreiben G. Volkonskijs an den Gesangslehrer Nozzari mit sich, vgl. Michail Glinka, Zapiski, hrsg. von A. S. Rozanov, Moskau 1988, S. 47.

122 Vgl.<https://ru.wikipedia.org/wiki/Волконский,_Григорий_Петрович>, 24.4.2016.

123 Vgl. CG 2, S. 541.

124 Vgl. CG 2, S. $759 f$. 
vielleicht beheben lassen könnte. ${ }^{125}$ Der russischen Berlioz-Forschung stehen damit noch einige Aufgaben bevor.

Als Quellenfund sei abschließend noch ein autographes Dokument vorgestellt, ein eigenhändiger Programmentwurf des Komponisten zu seinem Petersburger Konzert vom 3. / 15. März 1847: ${ }^{126}$

Programme

$1^{\circ}$ ouverture du Carnaval Romain

$2^{\mathrm{O}}$ Première partie de la Damnation de Faust

Légenge [= Légende] en 4 parties. Pastorale (plaines de Hongrie)

Ronde des Paysans

$3^{\circ}$ Deuxième partie de la Damnation de Faust

Marche Hongroise

Faust dans son cabinet (Nord de l'allemagne)

Chant de la Fête de Pâques

Cave de Leipzig Chœur

air de Mephistophélès

Concert des Sylphes (Bords de l'Elbe)

Chœurs de Soldates et d'Étudians

(Le role de Faust sera chanté par M Ricciardi, celui de Méphistophélès par M Versing

$4^{\circ} \quad$ Fragment instrumental de Romeo et Juliette

Symphonie-Dramatique avec chœurs.

Romeo seul, mélancolie, bruit lointain de Bal et de Concert. Grande fête chez Capulet.

$5^{\circ} \quad$ La belle voyageuse Ballade

Zaide Bolero

chantés par Mme Walcker

$6^{\mathrm{O}}$ Marche triomphale pour 2 orchestres.

on trouve des billets à $3 \mathrm{R}$ : et $2 \mathrm{R}$. chez Monsieur Bernard Editeur de Musique et chez M Berlioz maison Kosikowski au coin la petite Morskoy chez Deneveu.

Tous les morceaux du programme sont de la composition de M. Berlioz; ils seront exécutés sous sa direction par 300 musiciens.

125 Entdeckt wurde kürzlich etwa ein Brief des Komponisten an Ferdinand Friedland, vgl. Galina Petrova, "Neizvestnoe pi'smo Berlioza”, in: Starinnaja muzyka, 2015, Nr. 3, S. 25-27.

126 Handschriftenabteilung der Russischen Nationalbibliothek, fond 391: Kraevskij A. A., delo 747, folio 6. In der Übertragung ist die originale Orthographie beibehalten. Der Entwurf diente als Vorlage für die russische Konzertankündigung „Koncert Gospodina Berlioza. Segodnja, v ponedel'nik, 3-go marta, v zale Dvorjanskogo Sobranija, v 8 časov večera“, in: Severnaja pčela, 3.3.1847, Nr. 49, S. 2. 